\title{
Towards a Slow scholarship of teaching and learning in the South
}

Brenda Leibowitz ${ }^{\mathrm{a}}$ and Vivienne Bozalek ${ }^{\mathrm{b}}$

aFaculty of Education, University of Johannesburg, Auckland Park, Johannesburg, South Africa;

${ }^{b}$ Directorate of Teaching and Learning, University of the Western Cape, Bellville, Cape Town, South Africa

\begin{abstract}
Although the concept of a scholarship of teaching and learning (SOTL) has emanated from the global North, it is a relevant and useful concept in the global South. The concept was initiated in the 1990 s in the US. The original emphases in the seminal Boyer Report, on the integration of various forms of scholarship, the importance of intellectual thought and the collaborative nature of teaching have been subject to various distortions, in part due to the depredations of neoliberalism and performativity. We argue that Slow scholarship, which has resonances with Boyer's notions of the scholarship of teaching and learning provides much potential for reconceptualising SOTL in the South. These claims are explored via a case study set in South Africa, where academic developers at eleven higher education institutions covering the range of institutional types were interviewed.
\end{abstract}

Keywords: scholarship of teaching and learning; slow scholarship; South Africa; global South

It is exactly what Gayatri Spivak says, that you need the slow cooking of the soul, you know, if you really want to get anywhere. (Interview with respondent at one of the HEIs included in the study)

\section{Introduction}

The scholarship of teaching and learning (SOTL) originated as a field of practice to improve teaching and learning in higher education in the global North. It was initiated principally in the United States from the time of Boyer's 1990 seminal publication, Scholarship reconsidered: Priorities of the professoriate. Following this, it has been adopted in many other contexts, including in the global South, without due consideration of its appropriateness to the latter contexts. Consequently, there is a paucity of explicit accounts regarding the usefulness and ease or lack of execution of SOTL in southern contexts. With regard to SOTL in Latin America, where there has been an increase in articles about SOTL, Guzman (2017) makes the point that while these articles emanate from the South they are often not contextualised in relation to the issues of the South. SOTL is indeed appropriate 
and relevant for countries in the global South, such as South Africa, where the study reported on in this article is located, for similar reasons that it is relevant in the North: that it can enhance teaching and learning practices and that it can increase recognition for teaching as a scholarly activity. However in order for SOTL to realise its potential as a means to enhance teaching and learning in the South, there are suggestions which could be met by the concept of a Slow scholarship. This helps to take into account conditions of inequality and matters of difference, at the individual, disciplinary and institutional levels. It also helps to return to the key conceptualisations of scholarship raised by Boyer; and it helps to deal with the ravages of performative and technicist policies that are increasingly governing higher education practices. These issues will be discussed in more detail in the next section.

\section{The concept of the scholarship of teaching and learning}

The concept of the scholarship of teaching and learning appeared in the public domain through the publication of the Carnegie Foundation's 1990 report, Scholarship reconsidered: Priorities of the professoriate, authored by Ernest Boyer. He distinguished between the scholarship of discovery (knowledge for its own sake), the scholarship of integration (a focus on connectedness including inter-disciplinarity) the scholarship of application (how knowledge is applied, why knowledge matters and the intersection between theory and practice), and the scholarship of teaching (the intellectual engagement of the teacher and transformation and extension of knowledge) (Boyer 1990, 24).

SOTL was championed by two presidents of the Carnegie Foundation for Teaching and Learning, Ernest Boyer and Lee Shulman. Some of the key individuals who publicised SOTL and gave it more substance in the period of 1990-2011 in the United States, include Mary Huber, Pat Hutchings and Tony Ciccione, who wrote The Scholarship of Teaching and Learning Reconsidered: Institutional Integration and Impact in 2011. These individuals were closely associated with the Carnegie Foundation for Teaching and Learning, as well as with the American Association of Higher Education. Thus the concept of SOTL originated in and was publicised by prominent organisations in the global West. Individuals that gave much support to SOTL in the early years tended to have worked in more prestigious Western universities. This does not minimise the value of the concept - but it does suggest that its relevance and applicability in other, especially resource-constrained contexts, requires some attention. The translation of the term SOTL into other languages, academic cultures and settings needs to be engaged with for contexts outside of a Western epistemological context, for example in the East (Hoon and Looker 2013). With our emphasis on SOTL in the global South we do not wish to create the impression that there are no resource-constrained environments in the global North, but we are arguing that the confluence of material and cultural factors require particular attention to how SOTL is engaged with in the global South.

The 1990 Scholarship Reconsidered report is worth revisiting, as it contains important precepts that have become distorted or occluded in current writing on SOTL, and in the manner in which the concept has been applied at various institutions in South Africa. (We make this observation based on our professional work in support of SOTL at our own universities and others where we have run workshops or engaged with academics in 
academic programmes and short courses.) The most important of aspect of the 1990 report is the intention to dispense with the teaching versus research polarity:

thus, the most important obligation now confronting the nation's colleges and universities is to break out of the tired old teaching versus research debate and define, in more creative ways, what it means to be a scholar. (Boyer 1990, xii)

The report also affirms the importance of disciplinary expertise, as scholars need to be well versed in their fields in order to 'transform' and 'extend' knowledge (24). Despite this clear rejection of the teaching versus research tension, the concept and practice of SOTL has led to the distortion, where in many instances research (including published research) on teaching becomes pitted against disciplinary research, or against teaching and reflection on teaching (but without publication). Other significant imperatives in the report are: that scholarship be relevant and useful, namely that it 'respond more adequately to the urgent new realities both within the academy and beyond' (3); the need for creativity within scholarship; for interdisciplinary insight; and that professors work collaboratively, as a community of scholars, possibly within a national network. One of the most significant aspects of the report, in relation to Slow scholarship, is that it decries the imposed pressure for academics to publish, leading to burnout and competing obligations.

\section{A Slow scholarship of teaching and learning}

In the current climate of neoliberalism, Eurocentric and linear notions of time continue to dominate and colonise scholarship in university contexts. Southern and indigenous concepts of time are regarded as deficient and in need of development, as Shahjahan $(2015,491)$ puts it 'anything or anyone not aligned with history in forward motion must be converted, saved, developed, or improved'. The influence of market rationalities and corporate values of selfsufficient, rational individualism on higher education, makes Slow scholarship - which promotes the quality of relationships, grappling with ideas and recognising the importance of subjectivities, an anathema to the neoliberal academic enterprise. Slow scholarship, ${ }^{1}$ however, may be a productive way of reconceptualising SOTL in the South as it resonates with critiques of neo/liberal, humanist understandings of scholarship regarding higher education teaching and learning in a number of ways.

Firstly, it is very important to realise that 'Slow' has nothing to do with slowness/speed or duration, as Petrini (2007), the originator of the Slow Food Movement, made explicit. Rather it is about attentiveness, deliberation, thoughtfulness, open-ended inquiry, a receptive attitude, care-fullness, creativity, intensity, discernment, cultivating pleasure, and creating dialogues between the natural and social sciences (Berg and Seeber 2016; Boulous Walker 2016; Stengers 2011, http://slow-science.org/). The emphasis is quality rather than quantity, depth of engagement and a willingness to engage across differences of discipline and ideas.

Secondly, Slow scholarship and pedagogy emphasises what matters and what is meaningful, rather than what is economically expedient and efficient, thus amplifying the importance of ethico-political and aesthetic considerations of SOTL (Boulous Walker 2016; 
Payne and Wattchow 2009). Consequently, Slow scholarship is critical of academic development practices of offering workshops to academics on ways to cope with being overextended in their work, rather than practices which suggest that they should not be pressured to over extend themselves in the first place - see for example Berg and Seeber's (2016) critique of time management strategies for academics. In terms of SOTL, the expectation that writing retreats can be used to enable academics to churn out articles at a faster rate is a problematic one (Bozalek 2017). Slow scholarship is particularly suitable for Southern contexts because of its commitment to repoliticise and reinvigorate everyday practice in academia, as it is concerned about globalisation, ecological and environmental issues and colonialism (Berg and Seeber 2016). As Boulous Walker (2016, xv) notes about Slow reading, it is 'a political gesture as much as it is an aesthetic one.'

Thirdly, Slow scholarship and pedagogy are predicated on a relational ontology, where individual people and entities do not pre-exist relationships, but come into being through relationships. This is similar to many Southern and indigenous ways of seeing the world and scholarly work, which emphasise a relational ontology rather than focusing on individuals. Fourthly, Slow scholarship focuses on the affirmative and the vital, rather than pathologising and focusing on the abject other (Braidotti 2013)2 2

Fifthly, Slow scholarship works against dualisms of theory/practice, scholarship/pedagogy, subject/object, material/discursive, nature/culture, body/mind, using a holistic monist view of the world, regarding everything - human and more-than-human as entangled and vital, thus rethinking how scholarship in higher education might be configured (Barad 2007; Braidotti 2013; Payne and Wattchow 2009). Sixthly, Slow scholarship involves dwelling with, waiting or sitting/staying, steeping ourselves in things by re/turning, re/visiting, re/engaging, re/reading, re/writing and contemplating them anew (Barad 2010; Boulous Walker 2016). Finally, Slow scholarship is an apt logic for reconceptualising SOTL in the South in that it acknowledges that scholarship is a practice which is necessarily situated, affective, and embodied, troubling the conventionality of both what counts as knowledge and how knowledge is acquired and produced (Berg and Seeber 2016; Payne and Wattchow 2009).

\section{Context}

This study is set in the context of academic development in higher education in South Africa, where the two authors of this article work. Academic development in South Africa has been in existence since the 1980 s and has had various focii, including professional development, educational technology and a particularly strong focus on student support. We have both worked in the field for several decades, with particular attention to the encouragement of lecturers to conduct research on their teaching. In recent years we have included this work under the banner of 'SOTL'. We have run short courses, taught on postgraduate diplomas in higher education teaching and learning, and have conducted workshops and seminars on the topic. We have also published on the topic, where we allied SOTL with social justice and where we alluded to the struggles for many academics to come to grips with SOTL (Leibowitz and Bozalek 2016). SOTL is a well-known concept amongst academic developers and at 
several South African universities annual teaching and learning conferences are held, many with SOTL in the title.

South African has twenty-six public higher education institutions (HEIs), ranging from 100 years old to those which have been established in the last two years. Despite the increase in student numbers higher education remains underfunded, at .75\% of the GDP in 2011 as compared with the world average of .84\% (CHE 2016). As a system South African higher education is influenced by the unequal conditions in society, having one of the greatest disparities between rich and poor (Bhorat 2015). The society in which the institutions are located is presently volatile: dissatisfaction with service delivery and the persistent level of inequality has led to an increase in social unrest and protest, such that it has been argued that protest has possibly doubled between 2010 and 2015 (Demian 2015). Individual institutions continue to be influenced by disparities in funding, geographic location and institutional history (Bozalek and Boughey 2012). Various accounts of these institutional differences have been provided, for example between historically advantaged and historically disadvantaged universities; between those that are research-led or teachingoriented; merged and unmerged; urban and rural. The merged university is a descriptor which came into being after 2005, when a series of mergers required by the state reduced the number of institutions from 31 to 19 (recently increased to 26). A new category which came into being during this period was for 'comprehensive' universities, with a mixed teaching, research and professional focus. One categorisation advanced by Cooper (2015) and based on postgraduate enrolments and staff publications, suggests there were, in 2015, five 'upper band' or more research productive universities, seven 'middle band' and eleven 'lower band' universities. We contend, based on earlier research on the professional learning or professional development of academics at eight South African universities, that institutional context has a significant influence on how academics participate in activities designed to encourage their learning to teach (Leibowitz et al. 2015). This influence would extend to engagement in SOTL.

\section{Research design}

This study forms part of a larger National Research Foundation (NRF) project investigating professional development regarding teaching and learning in higher education across eight higher education institutions (HEIs) in South Africa. For this paper, eleven interviews were conducted with twelve academic development professional staff who were in some way responsible for promoting SOTL in their own institutions. Thus the interviewees are reporting on their own experiences of supporting the growth of SOTL at their institutions, as well as on their observations of the experience of academics with whom they interact. Informed consent was given by the interviewees at each of the HEIs for the use of their interview data for this study. The interviews were conducted across the three bands of universities and universities of technology in South Africa, as categorised after the mergers post-2000 (Cooper 2015). The three bands depicted in Table 1 below are based on postgraduate enrolments and staff publications. 
Four participants were interviewed from each of the three bands. In the table below we further categorise the institutions as 'research' or 'teaching oriented, universities of technology (UOTs)' or 'comprehensive', which is a combination of the other orientations.

The interviews were semi-structured and were based on a series of questions and prompts, which dealt with issues such as the interviewees' understandings of SOTL, the importance ascribed to it in the institutional context, how SOTL is supported and carried out, the challenges and enablements, and the perceived influence of the institutional type on SOTL programmes. The interviews were transcribed, then analysed independently by the two authors who discussed the findings in the light of relevant literature.

Table 1. Summary of participating universities.

\begin{tabular}{|c|c|c|}
\hline Band & No & Orientation/institution type \\
\hline \multirow{4}{*}{ One } & 1 & Research \\
\hline & 2 & Research \\
\hline & 3 & Research \\
\hline & 4 & Research \\
\hline \multirow{3}{*}{ Two } & 5.1 and 5.2 (two interviewees in one interview) & Comprehensive (Research, teaching, technology) \\
\hline & 6 & Teaching \\
\hline & 7 & Research \\
\hline \multirow[t]{4}{*}{ Three } & 8 & UOT \\
\hline & 9 & Teaching \\
\hline & 10 & UOT \\
\hline & 11 & UOT \\
\hline
\end{tabular}

\section{Findings}

\section{Understandings of SOTL}

Understandings of SOTL varied, and apparently the meaning shifts, depending on context, purpose, and the role of person who is interpreting the meaning of SOTL, according to the interviewee at University 2, Band 1 . We found that at least two interviewees made statements that revealed misinterpretations of Boyer's work, or that they had not read the report and attributed comments made by others to Boyer. SOTL was also often seen as indistinguishable from general professional development:

SOTL is being pushed because of concern that people had no teacher training and weren't reflecting and theorizing about their teaching. (Band 1, University 1)

It was also seen as indistinguishable from general academic development work:

SOTL is impossible for me to separate totally from [University Academic Development Centre]. (Band 2, University 7)

There was a strong emphasis in the interviews on SOTL promoting reflection, scholarship, and in some cases, SOTL promoting theorising about teaching and learning. According to the interviewees SOTL is about doing something meaningful - something that matters, from a 
Slow scholarship perspective. It is linked to one's own discipline and field. It is also linked to the professional field if one is at a UOT. It was also described as 'small scale studies' which link to larger issues (Band 2, University 7). This observation was interesting, as there has been a claim that SOTL work in South Africa focuses on the micro and meso levels, but needs to create greater links with the macro level, if transformation towards social justice is to occur (Samuel 2017).

One of the most interesting tensions to emerge from the interviews, was about making SOTL public, which involved sharing and disseminating practice:

We need to cultivate this openness through peer-review, through opening up all classrooms to become more public spaces, rather than private domains and scholarship demands that SOTL demands that as a practitioner. (Band 1, university 2)

Openness and sharing are two qualities closely aligned with Slow scholarship (Boulous Walker 2016).

As proposed by Slow scholars such as Berg and Seeber (2016) and Boulous Walker (2016), SOTL should be thoughtful and does not necessarily involve publication, as this interviewee suggests:

I don't think [it necessarily involves publication], I think it could be at a very practical level that you sensibly respond to what you are finding out, from say student feedback and you come up with ways of using that to improve change. But as I was saying, where the publication might come in it just wouldn't be "oh they have said that they don't understand what I am talking about, so let me talk more clearly". It would be something more substantive and thoughtful, and as I say more theoretical. (Band 3, University 11)

SOTL as Slow scholarship crucially involves reading, as well as writing, preferably collaboratively (Boulous Walker 2016):

So it is the reading and the writing, and in writing you come to understand things, and if you can also do that collaboratively it is a helpful process of coming to understand together. These are very time-consuming and long-term activities. (Band 2, University 6)

Thus Slow scholarship, with time to think, read, reread, dwell with, and write, rather than chasing after publications is what is important. But at the same time, there is a real possibility that academics might be denied the opportunity to engage in writing, either because of lack of time in the very teaching intensive universities, or due to lack of confidence with writing. This concern that academics involved in SOTL might not write, not because they are avoiding the pressures of performativity, but because they lack confidence or because they are overburdened with a high teaching load, is evident in the comment of an interviewee at a UOT who says colleagues 'were forced to develop papers and then from there they could develop articles. Just to encourage them to write' (Band 3, university 10). This 
raises interesting questions about how to encourage a more genuinely Slow scholarship in the South.

\section{How SOTL is promoted}

A full range of measures to support SOTL was mentioned by interviewees. Most interventions were implemented by individuals or academic development centres, and in some cases, by a Dean, Deputy Dean or academic developer in a faculty. The measures included: funding to incentivize; colloquia; visiting experts, writing collaboratively with academics, short courses and modules in postgraduate diplomas in higher education; large funded collaborative research projects, often cross institutional; seminar series; a university based blog; reading groups; integration into the university's teaching and learning strategy; integration with promotions criteria; one-on-one consultations ('individual chats'); departmental writing retreats; teaching and learning conferences and in one case, at a UOT a large institutional SOTL programme with mentors and mentees, utilising funding allocated to universities to build capacity. According to the interviewees in this institution, this has born fruit:

existing communities of practice that we currently have for example,...on classroom practice, the other one educational technology, curriculum design...these are some of our strengths in the project. Our stance is also that since the introduction of SOTL through the generous funding of the DHET [Department of Higher Education and Training] we have had 34 papers in 2015 .....and there are 32 in 2016. 41 papers were presented at our SOTL conference in 2016 and then 20 full papers submitted in 2016. (Band 3, university 10)

Another strategy involved mentoring a small group of people over the weekend in order to increase numbers of publications in SOTL: 'we take an idea from conception to production of the paper; by the 8th meeting the paper is ready for submission' (Band 1, university 2). This seems designed to 'deal with' or play into the corporatisation of SOTL - what a Slow scholarship might be very critical of, in that it is the quantity rather than the quality of publications that is focused upon.

\section{Why academics engage in SOTL}

Academics might engage in SOTL when there is no research trajectory in their particular field; when they see it as an escape route from lack of publications in their own field; when they've lost their academic identity; or as a career move:

they have lost that identity of a lead researcher in their area and now realize that this is another space where they can maybe begin to make a contribution, or they see themselves as going into more management positions and that something in higher education, some sort of qualification, and a little bit of publishing will make them 
attractive. So sort of a semi-strategic move that I think some of them are doing. (Band 2, university 7)

Some academics engage in SOTL out of concern for their students:

others are just concerned for their students..., the ones that come again and again and again to events. They actually care. So for them teaching is part of their caring for others. They would like to do it better. (Band 3, university 11)

From a more instrumental point of view academics engage in SOTL to improve their teaching and learning and get research outputs at the same time, and because there is financial support. From the point of view of Slow scholarship they do it because some of the schemes and support initiatives encourage them to engage with peers, making the process as conducive and supportive as possible.

\section{Enablements and constraints}

\section{Constraints and challenges}

One of the key challenges is that academics underestimate that SOTL is based on research procedures and disciplinary theory, like any other discipline. It can be seen as an easy route to research, a quick and easy fix, which is problematic from a Slow scholarship perspective:

New academics...are increasingly saying 'I can't go and get data, I don't have time for data production', they are seduced by the idea that 'I can use my own practice in order to generate research'. (Band 1, university 2)

Academics attend workshops and short courses, without a strong sense of what it is they want to research. Doing good SOTL requires having a strong understanding of teaching and learning, of educational research and research in general:

Academics that don't understand the educational paradigms. In some instances they don't have enough understanding of, let's call it social science research methods. And then in some instances they don't know enough about teaching and learning which is separate from educational paradigms. (Band 2 university 5.1)

A similar point, that SOTL requires scholarly attention, which is often underestimated or not realised by academics entering into the field, was made by an academic developer working within the health sciences:

I often get the feeling that when people are going to do research in education they are doing it because they see it as easy research. And then when you say to them "well have you thought about all the intervening variables?" And clearly they haven't and it's 
not easier research. In fact, I think it is much harder to do because you can't control so many of the things. (Band 1, university 4)

Although we locate the 'problem' with the underestimation of the intellectual labour and the scholarliness required of SOTL, the interviews also suggest that gatekeeping or overly specific and rigorous requirements from especially Education faculties might aggravate the problem. At one research-oriented university the process of getting a proposal for a dissertation accepted is very laborious, and expectations of how one writes up SOTL studies is limiting and prescriptive:

I think that some find the narrative realism that we use when we publish in journals of higher education, a lot of people find that quite alien.... Particularly the sort of style of writing that is most commonly used in education and SOTL in South Africa, which is clear, concise, all about communication, explicitness. I think many people find it a bit of a killjoy and not necessarily working well with the way they write in dense humanities and arts. (Band 2, university

7)

Some 'fast' approaches, especially workshops, do not provide solutions:

I have run workshops across faculties, talking about research methods and publication, conceptualising your project. I am not satisfied with them at all. Everyone comes wanting something different. It is quite instrumentalist - someone approaches you for a workshop in a faculty and you think it will start SOTL but it doesn't necessarily lead to the next step.

(Band 2, university 5)

What would be needed from a Slow scholarship perspective would be a great deal of attentiveness to and engagement with academics about critical processes needed to understand the complexity of SOTL. Deans, Deputy Deans and Heads of Department encourage their staff to take the route into SOTL as an easy option:

some think it is easier to do it - they have this notion that people are teaching anyway so why can't they just turn this into research? (Band 2, university 5)

This is effectively the corporatisation of the university working against Slow scholarship:

the idea that you must finish a PHD in three years, they not reading sufficiently, they not reading deeply, they not reading widely and so they coming half-baked and they can't connect ideas and so on and certainly in the PHD's the philosophy is totally absent. We are seduced by numbers, yes. By productivity and the more, the better looking it is. (Band 1, university 2) 
Academics and academic developers recognise that they are complying with market logic but find it difficult not to go along with this, as they are rewarded for it with funding:

using it because we know we want funding. So if we don't produce the metrics, so we are also trapped and we are implicated entrenching that practice. Ja we are complicit. (Band 1, university 2)

This marketisation and pressure aggravates the problem of academics not having a strong sense of the research involved in SOTL and not coming to grips with what is involved in meaningful SOTL either.

The adoption of SOTL for instrumental reasons, due to lack of a research identity for especially the more professional or technology-oriented fields of study, is stronger at UOTs and comprehensive universities:

The same factor that makes it conducive makes it non-conducive. Because it is a comprehensive university with areas not traditionally research-oriented people embrace SOTL but because it is a comprehensive there are a lot of people who don't have a depth of engagement with research. (Band 2, university 5)

Thus institutional context influences the take-up of SOTL. The challenges of limited capacity to support SOTL, student-teacher ratio and lack of time were also mentioned at previously disadvantaged universities. Academics feel that SOTL is an extra burden compounding a lack of time available for this work, which fits in nicely with an analysis of Slow versus a Fast approach to scholarship.

At one University of Technology, where there has been a tradition of authoritarian management, an interviewee mentioned the challenge of UOTs being regimented versus SOTL being creative and there not being a culture of staff getting higher degrees. This would pose particular challenges for a Slow scholarship.

There were a host of challenges to do with the understanding of SOTL, for example that middle-managers did not understand it and that some departments or faculties were not supportive:

It is not everyone that has really understood this whole idea of scholarship of teaching and learning. So we have got cases where in departments the middle managers especially the HODs they do not understand this link, they feel that maybe the lecturer is spending too much time working in communities, teaching and not spending too much time on research....I have got a case of someone we had to counsel, encourage and even to get the HOD to understand that these things are intertwined. (Band 3, university 9)

These challenges are not peculiar to South Africa, as can be deduced from the fact that similar constraints were mentioned in an Higher Education Academy Report on SOTL (Fanghanel et al. 2015). However a particularly South African slant is the association of SOTL with academic development, an endeavour in South Africa going back to the 1980s, 
which has often been associated with support for what has been termed 'academically disadvantaged' students. At one university SOTL was said to be affected by staff resentment against student weaknesses - in Braidotti's terms, the abject other. This view of students would also require strategising, how to pose this in affirmative terms. The lack of credibility regarding the scholarly value of academic development staff was mentioned, and therefore in some faculties SOTL was seen as 'less than' (Band 2, university 7). But the low status of academic development was not the only challenge. In some instances a challenge was a more general devaluing of teaching versus research as one interviewee at a research-oriented university explained:

we run lots of workshops, but often the response is poor and yet you look at the research workshops and they get a very good attendance. (Band 1, university 4)

The teaching versus research tension was mentioned by interviewees across the three bands. One interviewee attributed the tension to an attitude of economic expediency:

People will say to you "for every day that I spent doing a teaching workshop I could have written a paper, and it's so much money". And it's a cost, doing this kind of work comes at a cost, a real cost, and people have to weigh that up. And when they weigh it up, often it's SOTL that loses. (Band 1, university 3)

In some universities there was still the complaint that teaching was not valued for promotion or incorporated into promotion criteria. SOTL was also seen as less than, or 'nice to have' versus the industry connection in the UOTs (Band 3, university 8).

One of the difficulties with SOTL being seen as separate from scholarship is that it was supported in several institutions by grants from the Department of Higher Education and Training. This ring-fenced fund was managed on a project basis, unlike the usual approach to budgeting and funding. It was subject to the vagaries of institutional administrative processes such as the controlling of funds and gate-keeping, and making plans for when the funds arrived late. It was also due to the understanding of SOTL as being separated out from other aspects of scholarship, that one interviewee said, SOTL can 'can distance you from your discipline'.

A final point regarding the challenges was the observation by one of the interviewees that South African scholars do not engage sufficiently with scholars in other African countries, due to the hegemony of Western Eurocentric knowledge.

\section{Joys and enablements}

Interviewees described the joys as both instrumental, as well as akin to the intellectual nourishment of Slow scholarship:

because they look into research their benefit is to get some research outputs out of what they do as part of their research and these improve the research outputs of the 
institution. You know, also as they research their own practice they also promote, it also promotes personal growth. (Band 3, university 10)

By engaging in SOTL academics experienced pleasure in seeing their students learn. It affirmed their professional identities and helped them to feel that they are making a contribution:

For some academics there is a strong social justice element that, by becoming a lot more scholarly and by researching their practice and addressing really important issues they actually making a difference in the students. (Band 2, university 5)

At a university of technology academics were described as becoming more confident about curriculum design as well as about (the scholarship of) application:

I have also seen traces where there is increased empowerment among some academics, who have explored the curriculum through scholarship of teaching and learning, a degree of confidence in their interaction with industry to emphasize this is why this area of knowledge it's important. So they are not overpowered by the industry element in designing their curriculum. They have a voice now, a level of empowerment and confidence to be able to explain why the growth in this area of knowledge - Boyer talks about scholarship of application? That's very strong; it is significant for a UOT, especially with our work integrated learning components. (Band 3, university 8)

\section{Towards reconceptualising a Slow scholarship in the South}

All interviewees suggest that SOTL is an appropriate field to advance the professional learning of academics. The interviews highlighted that academics and those involved in learning centres do find pleasure, intensities and fulfilment in conducting SOTL in their contexts, as encouraged by Slow scholarship and pedagogy (Berg and Seeber 2016; Boulous Walker 2016).

There are clear risks however, according to the interviewees, of SOTL being promoted in a way that distorts the original intentions of Boyer's 1990 report. In many instances, due to the way SOTL has been interpreted in South Africa, it reinforces a teaching versus research tension and it encourages numeric research outputs rather than meaningful teaching and learning contributions. We argue that Slow scholarship can help to reconceptualise SOTL and to reduce these distortions. There are particular challenges associated with institutional context and differentiation, which are salient in a country like South Africa. Along with international neoliberal and performativity measures, these challenges work against the idea of a Slow scholarship. The particularities of these challenges, and how they interact with the concept of Slow scholarship, need to be followed up in further research. This article represents an early contribution on this matter.

We found using a Slow scholarship a particularly fruitful lens to analyse the interviews which we conducted. It was clear that corporatisation and its associated values of efficiency 
and productivity has had a deep effect on South African HEIs. This, in turn, has led to a pressure on academics to publish, and often they either regard SOTL as an easy and quick option, or they are encouraged in this direction by enthusiastic line managers. In this way, SOTL is often regarded as less than - less complicated than disciplinary research and something that one can engage in without steeping oneself in literature of the field. To counter this, it is crucial that SOTL is seen in a more affirmative light than it is portrayed by dominant institutional discourses, and as a meaningful contribution to scholarship. The institutional inequalities which were apparent in the interviews and the consequences of these, remind us of the importance of maintaining a receptive attitude to 'staying with the trouble' (Haraway 2016) in the ethics and politics of teaching and learning in higher education.

Slow scholarship has many resonances with Boyer's notions of SOTL, particularly the emphasis he placed on the importance of intellectual thought in teaching, and the teacher as a scholar and also a learner (Boyer 1990). The focus on transformation and collaborative practices as alternatives to assimilation and domestication to dominant modes are also common concerns of SOTL and a Slow scholarship. We believe that Slow scholarship is something which is worth pursuing for re/conceptualising SOTL in the South, as it can further enlarge and bring new insights for both an analysis of the current context and trajectory of SOTL in the South, as well as suggesting alternative ways of enacting SOTL. The emphasis of a deep, open and care-full disposition towards thinking, listening and paying due attention to the complexity and ambiguities of educational research, is an important contribution that Slow scholarship advocates. We realise that we are just at the beginning stages of contemplating how Slow pedagogical and scholarship practices might be configured and how these might be experimented with in our context, but we see the potential of deliberating on this. We hope that further research on a Slow SOTL in the South will contribute towards a meaningful realisation of SOTL as a global concept, and in this way, for southern theory to contribute to international scholarship (Connell 2007).

\section{Notes}

1. Slow scholarship is derived from the Slow Food Movement, a grassroots organisation which started in Italy in 1986, and subsequently spread internationally, providing alternatives to Fast food providing access to and enjoyment of eco-friendly and local produce and food cultures.

The movement also advocates just and fair practices and has been followed by other interest groups - Slow Art, Slow Travel, Slow Money, Slow Living (Parkins and Craig 2006) etc. Interest in the notion of 'Slow' Scholarship and Pedagogy in academia, as well as Slow Science (Stengers 2011, http://slow-science.org/) developed around 2010-2017 (see Bozalek 2017 for a fuller description of the fields in which Slow scholarship/pedagogy has been developed).

2. While Braidotti and other feminist materialists, besides Stengers (2011) do not explicitly refer to the Slow Movement and its application to scholarship and teaching and learning, many feminist materialist ideas cohere with those of the Slow Movement, including the focus on the affirmative, on joy and pleasure. 


\section{Acknowledgements}

This research was funded by the National Research Foundation (Grant No: 90353).

\section{Disclosure statement}

No potential conflict of interest was reported by the authors.

\section{Funding}

This research was funded by the National Research Foundation [grant number 90353; 105851]. 


\section{References}

Barad, K. 2007. Meeting the Universe Halfway: Quantum Physics and the Entanglement of Matter and Meaning. Durham: Duke University Press.

Barad, K. 2010. "Quantum Entanglements and Hauntological Relations of Inheritance: Dis/ Continuities, Space Time Enfoldings, and Justice-to-Come.” Derrida Today 3 (2): 240-268.

Berg, M., and B. K. Seeber. 2016. The Slow Professor: Challenging the Culture of Speed in the Academy. Toronto: University of Toronto Press.

Bhorat, H. 2015. "Fastcheck: Is South Africa the Most Unequal Country in the World?" The Conversation.

https://theconversation.com/factcheck-is-south-africa-the-most-unequal-societyinthe-world-48334.

Boulous Walker, M. 2016. Slow Philosophy: Reading Against the Institution. London: Bloomsbury.

Boyer, E. 1990. Scholarship Reconsidered: Priorities of the Professoriate. New York: The Carnegie Foundation. Jossey Bass.

Bozalek, V. 2017. "Slow Scholarship in Writing Retreats: A Diffractive Methodology for Response-Able Pedagogies." South African Journal of Higher Education 31 (2): 4057 .

Bozalek, V., and C. Boughey. 2012. "(Mis)Framing Higher Education in South Africa." Social Policy \& Administration 46 (6): 688-703. doi:10.1111/j.1467-9515.2012.00863.

Braidotti, R. 2013. The Posthuman. Cambridge: Polity Press.

CHE (Council on Higher Education). 2016. South African Higher Education Reviewed: Two Decades of Democracy. Pretoria: Council on Higher Education.

Connell, R. 2007. Southern Theory. Malden: Polity.

Cooper, D. 2015. "Social Justice and South African University Student Enrolment Data by 'Race', 1998-2012: From 'Skewed Revolution' to 'Stalled Revolution'.” Higher Education Quarterly 69 (3): 237-262.

Demian, M. 2015. “Have Protests in South Africa Nearly Doubled Since 2010?” Africa Check. https://africacheck.org/reports/have-protests-in-south-africa-nearly-doubled-since2010/.

Fanghanel, J., S. McGowan, P. Parker, C. McConnell, J. Potter, W. Locke, and M. Healey. 2015 .

Literature Review. Defining and Supporting the Scholarship of Teaching and Learning (SoTL): A Sector-Wide Study. York: Higher Education Academy.

Guzman, Carolina. 2017. "The Geopolitics of Research in Teaching and Learning in the University in Latin-America." SOTL in the South 1 (1): 4-18.

Haraway, D. 2016. Staying with the Trouble: Making Kin in the Chthulucene. Durham: Duke University Press.

Hoon, C. H., and P. Looker. 2013. "On the Margins of SoTL Discourse: An Asian Perspective." Teaching and Learning Inquiry 1 (1): 131-145.

Hutchings, P., M. Taylor Huber, and A. Ciccone. 2011. The Scholarship of Teaching and 
Learning Reconsidered: Institutional Integration and Impact. San Francisco: Jossey Bass.

Leibowitz, B., and V. Bozalek. 2016. "The Scholarship of Teaching and Learning From a Social Justice Perspective.” Teaching in Higher Education 21 (2): 109-122. doi:10.1080/13562517.2015.1115971.

Leibowitz, B., V. Bozalek, C. Winberg, and S. van Schalkwyk. 2015. "Institutional Context Matters: The Professional Development of Academics as Teachers in South African Higher Education." Higher Education 69 (2): 315-330. doi:10.1007/s10734-014-9777-2.

Parkins, W., and G. Craig. 2006. Slow Living. Oxford: Berg.

Payne, P. G., and B. Wattchow. 2009. "Phenomenological Deconstruction, Slow Pedagogy, and the Corporeal Turn in Wild Environmental/Outdoor Education." Canadian Journal of Environmental Education (14): 15-32.

Petrini, C. 2007. Slow Food Nation: Why Our Food Should Be Good, Clean, and Fair. New York: Rizzoli Ex Libris.

Samuel, M. 2017. "Developing a Syntax for SOTL.” SOTL in the South 1 (1): 19-38.

Shahjahan, R. A. 2015. "Being 'Lazy' and Slowing Down: Toward Decolonizing Time, Our Body, and Pedagogy." Educational Philosophy and Theory 47 (5): 488-501.

Stengers, I. 2011. “'Another Science is Possible!' A Plea for Slow Science.” Faculté de Philosophie et Lettres, ULB, Inaugural lecture; Chair Willy Calewaert 2011-2012 (VUB). 